\title{
Modeling Climate Variability Influence on River Regime in Upper Njoro Catchment, Kenya
}

\author{
Edwin Otieno Amisi", Peter Musula Kundu, Raphael Muli Wambua
}

Department of Agricultural Engineering, Egerton University, Nakuru, Kenya

Email address:

edwineamisi@gmail.com (E. O. Amisi)

${ }^{*}$ Corresponding author

\section{To cite this article:}

Edwin Otieno Amisi, Peter Musula Kundu, Raphael Muli Wambua. Modeling Climate Variability Influence on River Regime in Upper Njoro Catchment, Kenya. Journal of Civil, Construction and Environmental Engineering. Vol. 5, No. 5, 2020, pp. 126-137.

doi: $10.11648 /$ j.jccee.20200505.14

Received: September 16, 2020; Accepted: October 5, 2020; Published: October 13, 2020

\begin{abstract}
To establish the effect of climate variability on annual discharge in Upper Njoro Catchment, hybrid models were developed by coupling Soil and Water Assessment Tool and Artificial Neural Networks. Daily surface runoff, lateral flow, and groundwater flow were first simulated with SWAT for the period (1978-1987) using climate variables from Egerton University weather station and LULC of 1978. The daily hydrologic variables simulated without calibration and validation of SWAT and observed discharge data were then used for ANN training, which led to the creation of discharge generation hybrid models for the dry, wet and wetter seasons. SWAT_ANN models generated discharges were compared with observed data and the performance rating were achieved at $\mathrm{R}^{2}(0.94,0.91,0.92)$ and NSE $(0.89,0.87,0.87)$ for DJFM, AMJJ, and ASON seasons respectively. SUFI-2 algorithm in SWAT-CUP was run separately to compare the performance of SWAT with that of SWAT_ANN. SWAT-CUP sensitivity analysis revealed satisfactory values of both the p-factor $(0.61)$ and the r-factor $(0.69)$. Calibration and validation of monthly streamflow were realized at $\mathrm{R}^{2}(0.86$ and 0.78$)$ and NSE $(0.83$ and 0.74$)$. The results showed that coupling SWAT and ANN improved flow prediction. Further, the potential of the SWAT_ANN modeling approach to separate the influence of climate variability on river regime from the effect of LULC was evaluated by comparing trends in the differences between observed and SWAT_ANN simulated monthly streamflow with trends of the quantified LULC changes. The findings provided sufficient evidence that the SWAT_ANN modeling approach was reliable and could also be applied to detect changes in LULC.
\end{abstract}

Keywords: Climate Variability, Land Use, River Regime, SWAT-CUP, SWAT, SWAT_ANN

\section{Introduction}

Although water scarcity has been identified as one of the major challenges the world is facing in the $21^{\text {st }}$ century, the management and planning of water resources is becoming more problematic due to the uncertainties of climate variability and land use/land cover (LULC) changes [6]. According to Schipper [42], climate variability and LULC changes continue to alter hydrological regimes by changing precipitation partitioning patterns into extreme increased or declined overland flow, actual evapotranspiration, surface runoff, subsurface flow, and groundwater outflow and recharge, thus annual river discharge dramatic fluctuations. The changes in the hydrological regime are challenging because climate variability and land-use change operate at different temporal and spatial scales. Moreover, the effect of land-use change and climate change might compensate or strengthens each other. Besides, they both might occur in parallel and there is uncertainty to correctly attribute observed changes in discharge to climate change or land-use change [5, 37].

Like many other places in the world, the River Njoro Catchment of Kenya is also experiencing the challenges of climate variability and LULC changes. There is a steady recognition that surface and groundwater sources are declining. River Njoro, which originates from Mau Forest Complex into Lake Nakuru is experiencing drastic changes in discharge and sometimes doesn't flow throughout the year. Previous research by Kundu [27] and Mwetu [31] link the cause of streamflow decline to LULC changes in the 
upstream. However, there is scanty quantifiable information on the influence of climate variability on spatial and temporal distribution of streamflow. Also, there is no technique for attribution of changes in discharge to climate and land-use changes. Therefore, modeling climate variability influence on river regime is important in Upper Njoro Catchment, because it provides useful and relevant insights into the impact of climate variability on streamflow, which may perhaps enlighten decision making in catchment rehabilitation, mitigation approaches, strategic planning, monitoring, and management of water resources. Also, establishing the influence of climate variability is imperative since it aids the detection of changes in land use and land cover in a catchment.

Hydrological modeling is key to the optimization and operation of water resources [29]. Several statistical, empirical, and conceptual streamflow prediction models have been developed for decision support in water management. Statistical techniques, such as linear regression-based approaches are constrained, simplistic, and have limited capacity to handle non-linear relationships. Conceptual hydrologic models are always considered the best alternative because they take into account hydrologic processes through mathematical formulations. The assertion by Devia et al. [7] affirms the importance of the developed conceptual hydrological models, for example, Soil and Water Assessment Tool (SWAT), Water Evaluation and Planning (WEAP), and Spatial Processes in Hydrology (SPHY) and the key role they play in integrated water resources management solutions.

Many researchers have demonstrated the ability of the SWAT model to replicate hydrologic loads at a variety of spatial scales on an annual and monthly basis $[9,28]$. The model has been applied successfully in many river basins in Kenya, which include Sondu [20, 41], Tana [18], Nzoia [15], and Njoro [31]. However, SWAT performance depends on the quality of input data model parameters, sensitivity analysis, calibration, and validation procedures. Moreover, a broad range of input values and parameters, and their complex interactions make calibration and validation procedures complicated, technical, hectic, and timeconsuming [40].

An alternative coupling approach of SWAT with lumped models such as Artificial Neural Network (ANN) can be an alternative better predictor of streamflow [33]. Combining the two models helps in overcoming the shortcomings of each model. Besides improved performance, it leads to the development of a discharge generation tool which eliminates calibration and validation processes for SWAT. A study by Khashei et al. [24] in their both empirical and theoretical models integration findings, indicated that combining or coupling models effectively improve their predictive performance, particularly when the models in the ensemble are quite different. As demonstrated by Liu [36], ANN models are better because of their properties such as high fault tolerance, the capability of adaptive learning, selforganization, real-time operation, robust performance in dealing with noisy input patterns, and the ability to generalize from the input data which make them a reliable option for probability predictions. ANNs have been widely applied in hydrological studies in the recent past $[16,12,13,21,26,38$, 44].

Therefore, this paper provides an approach to modeling the influence of climate variability on the river regime by coupling SWAT and ANN. It is a modeling process which only filters the influence of climatic condition on streamflow since there is no variation of LULC. This kind of modeling technique is an exploration of an approach introduced by Isik et al. [17] who combined the Soil Conservation Service (SCS) Curve Number $(\mathrm{CN})$ to predict the impact of land-use change on daily discharge. The major difference is that this study was on simulation of daily discharge under a condition of the same LULC (of 1978) for different climatic scenarios.

\section{Materials and Methods}

\subsection{Description of the Study Area}

Upper Njoro Catchment is located between Longitudes $35^{\circ}$ $50^{\prime} \mathrm{E}$ and $36^{\circ} 00^{\prime} \mathrm{E}$ and Latitudes $0^{\circ} 21^{\prime} \mathrm{S}$ and $0^{\circ} 34^{\prime} \mathrm{S}$ (Figure 1). The catchment occupies zone $36 \mathrm{~S}$ of the Universal Transverse Mercator (UTM) grids in the east, and it lies between the upper slopes of the Mau escarpment and Rongai-Njoro plains. Upper Njoro Catchment topography is mainly rolling land with slopes ranging from $3 \%$ at the plains to $54 \%$ in the topmost escarpment. It is drained by river Njoro, which descends from an altitude of about $3079 \mathrm{~m}$ above mean sea level (msl) at its source in the Eastern Mau Hills to about $1774 \mathrm{~m}$ as it drains into Lake Nakuru. Egerton University weather station (EU) (ID. 9035092) located near the river gauging station (2FC05) has relatively good meteorological data that was used in modeling. According to EU weather station, the average annual precipitation in the area was $1029 \mathrm{~mm}$ for the 40 years (1978-2017). The rainfall pattern is tri-modal with peaks in April, August, and November. Also, the mean annual wind speed, relative humidity, maximum, and minimum air temperatures were 5.1 $\mathrm{km} / \mathrm{h}, 64.61 \%, 23.4^{\circ} \mathrm{C}$, and $13.37^{\circ} \mathrm{C}$ respectively.

\subsection{Hydrologic Modeling}

\subsubsection{Soil and Water Assessment Tool}

Soil and Water Assessment Tool is a basin-scale deterministic hydrologic model designed to simulate the flow of water, agricultural chemical yields, crop growth, and sediments in a watershed. It is a semi-distributed model, which operates at sub-daily and daily time step [2]. In SWAT, for hydrologic modeling, the catchment is divided into multiple sub-catchments, which are further subdivided into hydrologic response units (HRUs). Hydrologic response units are lumped land within a sub-catchment which consists of homogeneous land cover, management, slope, and soil characteristics [34]. SWAT inputs are based on the topography of the area (digital elevation model), climatic factors, land use, and soil type. 


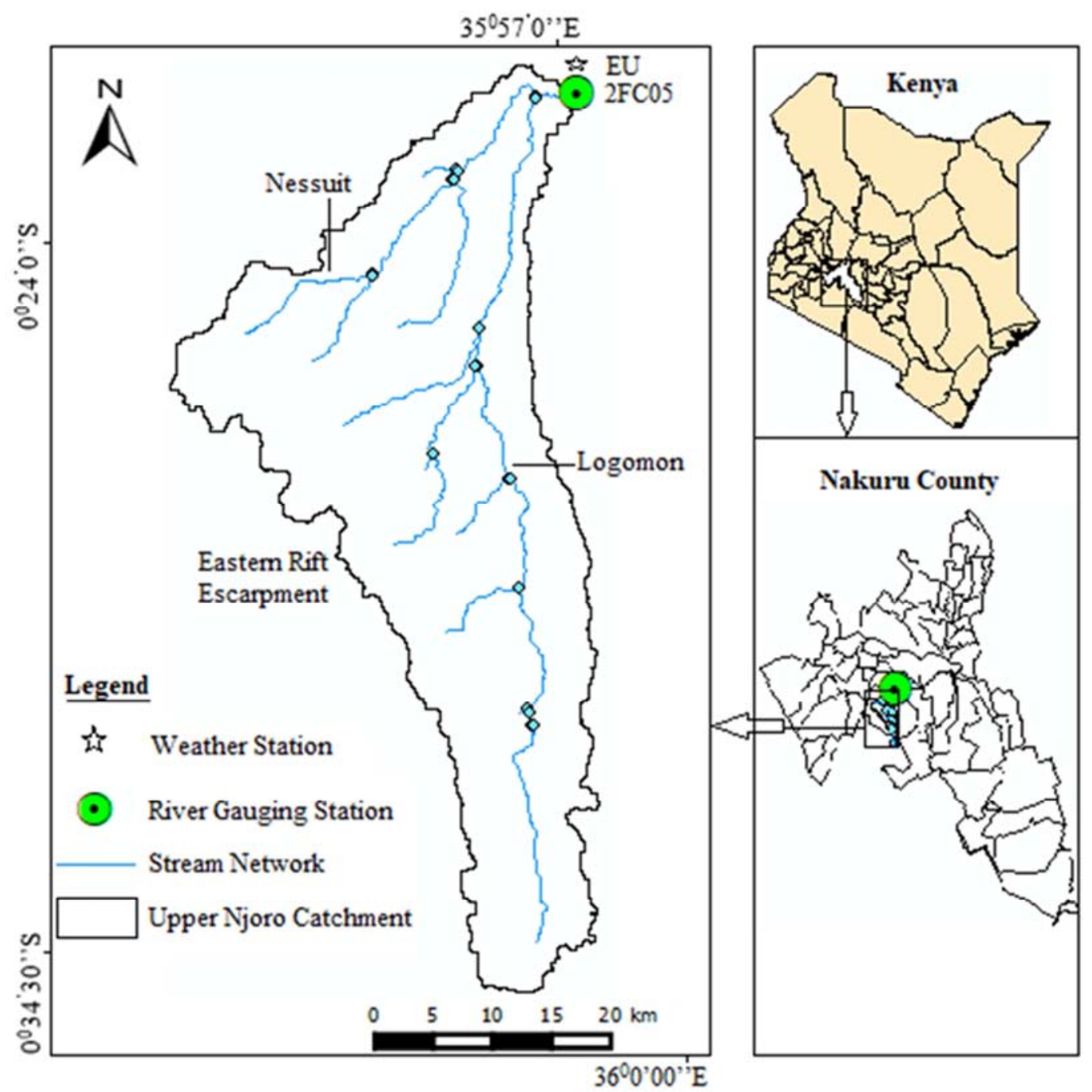

Figure 1. Location of Upper Njoro Catchment, Kenya.

Digital Elevation Model is an essential spatial input for automatic extraction of topographic parameters. Land use and land cover control the hydrological response and condition of the catchment. Soil data is very important because soil properties affect infiltration, surface and subsurface transport of water, and percolation. Climatic inputs used in SWAT include daily wind speed, solar radiation, relative humidity, precipitation, minimum and maximum temperature. The minimum and maximum air temperatures are necessary for the computation of daily water and soil temperatures. Precipitation being the main process through which water enters the land phase component of the hydrologic cycle, is very key in the determination of water balance, and therefore, its amount and distribution, in both space and time must be accurately simulated. Wind speed, solar radiation, and relative humidity use in SWAT depend majorly on the method selected for evapotranspiration estimation. For each HRU, the overall hydrologic balance is simulated. The hydrologic variables are simulated based on the soil water balance equation [2], which is given as,

$$
S W_{t}=S W+\sum_{i=1}^{n}\left(R_{d a y}-Q_{i}-E_{a}-P_{i}-Q R_{i}\right)
$$

Where;

$\mathrm{SW}=$ soil water content $[\mathrm{mm}]$

$t=$ time [days]

$R_{\text {day }}=$ amount of precipitation $[\mathrm{mm}]$

$Q_{i}=$ amount of surface runoff $[\mathrm{mm}]$

$E_{a}=$ amount of evapotranspiration [mm]

$P_{i}=$ amount of percolation $[\mathrm{mm}]$

$Q R_{i}=$ amount of return flow $[\mathrm{mm}]$

\subsubsection{SWAT Model Setup and Run}

The $30 \mathrm{~m}$ spatial resolution Shuttle Radar Topography Mission-Digital Elevation Model (SRTM-DEM) was obtained from https://earthexplorer.asgs.gov/. Using the ArcMap platform, the acquired DEM was then clipped to reduce the extent of coverage to the study area (Upper Njoro Catchment) and projected to the local Universal Transverse Mercator (UTM) that was a selected Coordinate Reference 
System (CRS) (WGS 84/ UTM zone 36S) (Figure 2). It was used to discretized and parameterized sub-catchments and stream networks, as well as the derivation of the length, average elevation, mean slope, width, and area (Figure 2). The soil data obtained from FAO was clipped to the area of interest, rasterized, and projected to WGS84 Zone 36S (Figure 2). LULC map of 1978 was obtained by supervised classification using ArcMap on the imagery taken by MultiSpectral Scanner (MSS) sensor aboard Landsat (L 1-4) that classification was done into the following categories, Forest, Mixed Grassland/Shrubs, and Mixed Agriculture/Pasture (Figure 2). Hydrologic response units' inputs were derived from the combination of slope, soil, and LULC data. The daily observed climate variables used were from 1978 to 1987 from the EU weather station. Hydrologic components of river discharge (surface runoff, lateral flow, and groundwater flow) were then simulated daily from 1978 to 1987 with the parameters set at default values. (a) Topographic map

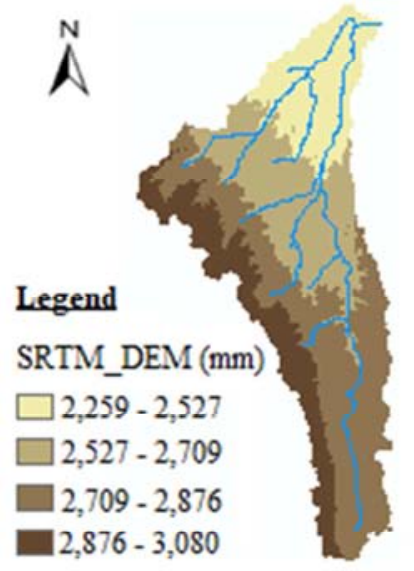

(b) Hydrologic soil map

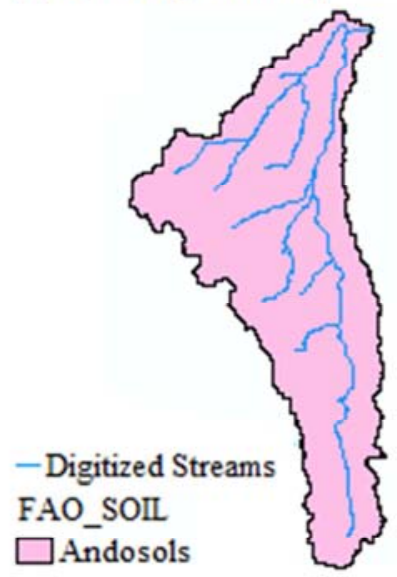

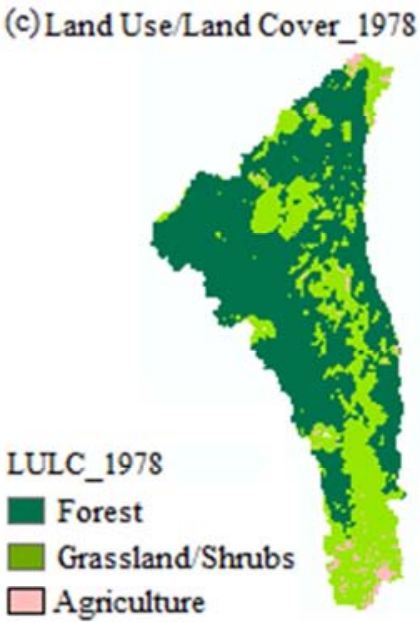

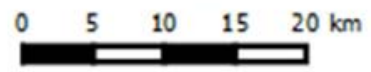

has four channels, (two visible, and two infrared). The

Figure 2. Topographic, Soil, and LULC maps of Upper Njoro Catchments, Kenya.

\subsection{Coupling SWAT and ANN}

To improve and obtain daily discharge simulations from climate influence, hybrid multivariate models based on the Soil and Water Assessment Tool and Artificial Neural Network were then developed for different seasons (December to March, April to July, and August to November). The category of the three seasons (DJFM, AMJJ, and ASON) were used in obtaining optimum performance of ANN during training. This was important to reflect the sensitivity of the impact of seasonal weather patterns on baseflow and stormflow. The first procedure in the SWAT_ANN modeling approach was the simulation of surface runoff (SURQ), lateral flow (LATQ), and groundwater flow (GWQ) components of discharge by the SWAT model with default values of the parameters. A feed-forward multi-layer perceptron referred to as Radial Basis Function Neural Network (RBFNN) (Figure 3) was adapted for this study. SWAT was applied as a transfer function to combine DEM, LULC, soil, and climatic data to produce ANN model inputs. The simulated SURQ, LATQ, and GWQ at day (t) from SWAT for the period (1978 to 1987) served as inputs to the RBFNN model and observed daily discharge data for the period (1978 to 1987) at the river gauging station (2FC05) from the Water Resources Authority used as the RBFNN target data.

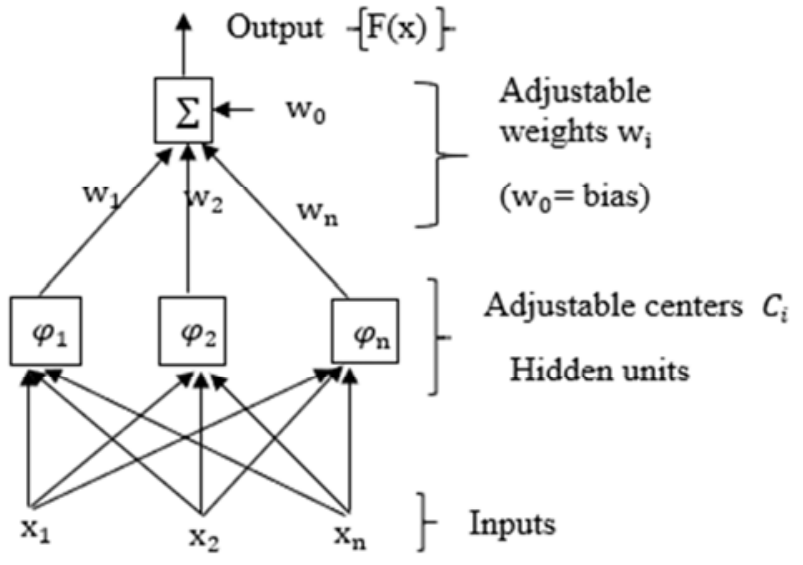

Figure 3. Radial Basis Function Neural Network topology.

Each unit in the hidden neurons mathematically described as,

$$
\phi_{i}(x)=\left(\left\|x-C_{i}\right\|\right), i=1,2, \ldots, n
$$

Where;

$x=$ n-dimensional vector

$C_{i}=$ n-dimensional vector called the center of the RBF

\|\|$=$ Euclidean distance, and is a univariate function, defined for positive input values

Gaussian basis function was selected for this study and it is 
defined as;

$$
\phi_{i}(x)=\exp \left(-\frac{1}{2 \sigma_{i}^{2}}\left(\left\|x-C_{i}\right\|^{2}\right)\right), i=1,2, \ldots, n
$$

Radial basis function network output was then given by Eq. 4 .

$$
F(x)=\sum_{i=1}^{j} \mathcal{W}_{i}^{\phi(x)}
$$

The error backpropagation algorithm, a gradient descent algorithm was selected for the training because it is exemplary robust and accurate. Optimization was obtained when applied in a sequential training mode. This effectively permitted the set of weights to be successively modified after each exemplar processing as,

$$
\mathcal{W}_{i j}(n+1)=\mathcal{W}_{i j}(n)+\Delta \mathcal{W}_{i j}(n)
$$

Where, $\Delta_{\mathcal{W}_{i j}}(n)$ was the corresponding weight change, given as,

$$
{ }^{\Delta} \mathcal{W}_{i j}(x)=\alpha\left[{ }^{\Delta} \mathcal{W}_{i j}(n-1)\right]+\eta \boldsymbol{\delta}_{j}(n) y_{i}^{l-i}(n)
$$

Where;

$\alpha=$ momentum coefficient

$\eta=$ learning rate

$\delta_{j}(n)=$ local gradient for the node $\mathrm{j}$ in layer $l$.

The challenge of computing synaptic weights may be considered as a non-linear optimization problem without constraints. The mean squared error (MSE) function was then used as a convenient objective function (Eq. 7)

$$
M S E=\frac{1}{2 N_{n}} \sum_{n=1}^{N_{p}} \sum_{j=1}^{m_{2}}\left(q_{i}(n)-F_{i}(x)\right)^{2}
$$

Where;

$N_{n}=$ number of patterns feed into a network

$q_{i}(n)=$ target value for the node $i$

$F_{i}(x)=$ simulated value for $\mathrm{t}$

\subsubsection{Discharge Generation Model}

During training, historical data was used for modeling by training (Equation 4). The difference between simulated and observed values led to the residues series $\{\varepsilon\}_{t}$. The residual series were then modeled as cross-correlated and normally distributed series with means statistically equivalent to zero and their respective variances. The multivariate random component of the RBFNN was then expressed as,

$$
\{\mathcal{E}\}_{t}=\mathrm{B}\{\xi\}_{\{t\}}
$$

Since

$$
B B^{T}=\Sigma
$$

Where $\{\varepsilon\}_{t}$ the uncorrelated and normally distributed random signal with (0) variance and statistically equal to $1, \Sigma$ was the covariance matrix of the observed residual series, and it was the Gramian matrix of matrix B. The last one was obtained by solving the matrix equation.

The multivariate models for synthetic simulation of daily discharge (Q) under the influence of different climatic scenarios were then built by the combination of radial basis network output and a multivariate random component. They were assembled as,

$$
\{Q\}=F(x)+\{\varepsilon\}
$$

Where;

$F(x)=$ standardized and normalized synthetic values computed from Eq. (4)

$\{\varepsilon\}=$ synthetic residuals calculated from Equation (8).

All the activities and programming of the hybrid model development $(\{Q\}=F(x)+\{\varepsilon\})$ training, testing, and validation were carried out in MATLAB. SWAT_ANN Models performances were assessed by the use of the Coefficient of Determination $\left(\mathrm{R}^{2}\right)$ and Nash-Sutcliffe Efficiency (NSE) as expressed in Equation. 11 and 12.

The $\mathrm{R}^{2}$ value measures how well the simulated versus observed regression line approaches an ideal match and ranges from 0 to 1 , with a value of 0 indicating no correlation and a value of 1 representing that the predicted dispersion equals the measured dispersion. The NSE ranges from $-\infty$ to 1 and measures how well the simulated versus observed data match the 1:1 line (regression line with slope equal to 1). Considering the daily time step modeling, the performance evaluation of models developed were rated according to the recommendation by Kalin et al. [22]. Where, $0.7<\mathrm{NSE} \leq$ $1.000 .5<\mathrm{NSE} \leq 0.7,0.3<\mathrm{NSE} \leq 0.5$, and NSE $\leq 0.3$ were considered to be very good, good, satisfactory and unsatisfactory respectively.

$$
\begin{gathered}
R^{2}=\frac{\left[\sum_{i=1}^{n}\left(q_{i}^{o b s}-q_{i}^{a v g}\right)\left(Q_{i}^{\text {sim }}-Q_{i}^{a v g}\right)\right]^{2}}{\sum_{i=1}^{n}\left(q_{i}^{o b s}-q_{i}^{a v g}\right)^{2} \sum_{i=1}^{n}\left(Q_{i}^{s i m}-Q_{i}^{a v g}\right)^{2}} \\
N S E=1-\frac{\sum_{i=1}^{n}\left(q_{i}^{o b s}-Q_{i}^{\text {sim }}\right)^{2}}{\sum_{i=1}^{n}\left(q_{i}^{o b s}-q_{i}^{a v g}\right)^{2}}
\end{gathered}
$$

Where;

$n=$ total number of observations

$q_{i}^{o b s}=$ observed discharge

$q_{i}^{a v g=\text { average of the observed data }}$

$Q_{i}^{\text {sim }}=$ simulated discharge

$Q_{i}^{a v g}=$ average of the simulated data 


\subsubsection{SWAT-CUP}

To compare and assess the prediction accuracy of the SWAN_ANN modeling approach to SWAT, sensitivity analysis, calibration, and validation was also carried out using the Soil and Water Assessment Tool Calibration Uncertainty Procedure (SWAT-CUP). The computation of SWAT parameters related to streamflow was conducted by the domain parameter fitting algorithm (SUFI-2). As eluded by Khoi and Thom [25], SUFI-2 accounts for nearly all uncertainties sources. The Water Resources Authority's daily discharge data at the river gauging station (2FC05) was used for the calibration of SWAT. SWAT performance was assessed by the use of $\mathrm{R}^{2}$ and NSE.

\subsection{Evaluation of SWAT_ANN Modelling Approach}

The first evaluation was done by calculating the difference between the observed monthly streamflow and SWAT ANN simulated streamflow under the influence of changing climatic scenarios with a constant condition of LULC of 1978 for the period (1978-1999). This period (1978-1999) was selected because it is the only duration where available monthly streamflow data are relatively reliable and consistent. Also, monthly discharges were selected because of the missing data challenges in observed streamflow. The point where noticeable significant deviation began was then marked and observed trends in LULC changes were analyzed to ascertain the existence of changes in streamflow as a result of alteration in LULC. Quantification of spatial and temporal dynamics of LULC changes in Upper Njoro Catchment from 1978 to 2002 using remotely sensed data was done by supervised classification in ArcMap. Downloaded satellite images were first clipped and resampled to cover Upper Njoro Catchment. Then, they were projected to WGS 84/UTM zone 36 s.

The following steps were then carried out in ArcMap applications to achieve supervised classification for the LULC. Layer stacking, sub-setting, atmospheric corrections, geometric correction, image enhancement, a hybrid classification (Maximum likelihood classification), assessment of classification accuracy, and Post-processing of Landsat imagery. LULC categories for Landsat images of 1986, 1989, 1995, and 2002 classified were Forest, Mixed Grassland/Shrubs, and Mixed Agriculture/Pasture. The change in coverage of the land between the land cover maps was calculated by simple subtraction of the individual LULC types. Also, for accuracy purposes documented land-use changes by Baldyga [4] and Mwetu [31] were analyzed. Baldyga [4] assessed Land cover change impacts in Kenya's Upper Njoro Catchment using remote sensing and hydrologic Modelling within the periods (1986-2003). Mwetu et al. [31] approximated Spatio-temporal dynamics of land use in Upper Njoro Catchment from 1973 to 2000 using remotely sensed data.

\section{Results and Discussion}

\subsection{SWAT_ANN Performance}

The coupled approach of SWAT and ANN showed improved prediction efficiency even though the performance was categorized into dry and wet seasons (Figure 4). The highest and lowest values of $\mathrm{R}^{2}(0.94$ and 0.91$)$ showed that the model captured monthly discharge at a very good level. It was inferred that the SWAT_ANN approach was capable of explaining at least $94 \%$ of the variance of monthly discharge values which implied that the simulated and observed discharges had relatively the same Spatio-temporal pattern. The NSE values as shown for each season revealed a relatively excellent match between the predicted and observed monthly discharges.

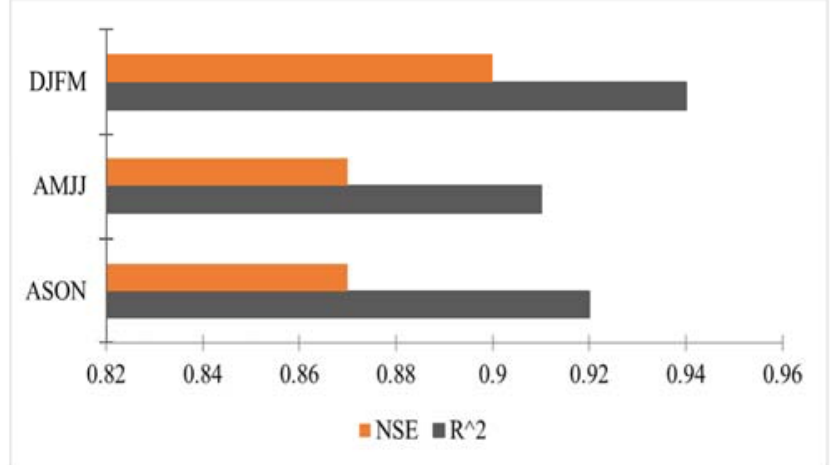

Figure 4. Coupled model (SWAT_ANN) performance (NSE and $R^{2}$ values).

According to Kalin et al. [22] ratings, these statistical indicators revealed a very good rating performance of SWAT_ANN for simulation of streamflow. The performance agreed with a previous study by Noor and Kalin [33] who developed a hybrid model by coupling SWAT and ANN for daily flow prediction in unmonitored watersheds. They reported that out of twenty-nine total tested watersheds, $83 \%$ and $62 \%$ of them had NSE values above 0.5 during the warm and cool seasons respectively. Moreover, Khalid [23] confirmed that the coupling of SWAT and ANN outputs improved the results of the streamflow mostly at the peak value. Similar performance has also been reported by Senent et al. [43], who carried out a prediction of instantaneous peak flow by coupling machine-learning techniques with the SWAT model in areas where sub-daily observational data were scarce. Their experimental and simulated data correlated with coefficients of 0.86 to 0.88 .

\subsection{SWAT Model Performance}

The protocols applied to calibrate the SWAT model were to minimize the extreme variations between observed data and simulated discharge values by adjustments of the sensitive parameters within the allowable ranges (Table 1). SUFI-2 algorithm of SWAT_CUP sensitivity analysis as shown in Table 1 indicated that the SCS runoff curve number for moisture condition II (CN2) was the most sensitive parameter while the maximum canopy storage parameter (CANMX.hru) was the least sensitive parameter. The uncertainty analysis results indicated satisfactory values of both the p-factor (0.61) and the r-factor (0.69).

The values of the Coefficient of Determination $\left(R^{2}\right)$ for 
calibration and validation of mean monthly discharges were 0.86 and 0.79 respectively. Nash-Sutcliffe Efficiency values for calibration and validation were 0.83 and 0.76 for monthly discharge respectively. The statistical performance of the SWAT model revealed relatively better linear covariation and that simulated and observed streamflow values had fairly similar Spatio-temporal patterns. SWAT performance was acceptable as per the Moriasi et al. [30] ratings and recommendations. These sets of SWAT performance statistics for sensitivity analysis, calibration, and validation were consistent with the findings of the previous studies such as Mwetu [31]. Calibration and uncertainty analysis remained to be a challenge since the whole process depended on the response of inputs during adjustments, the number of iterations, the quality of observed data, and the period for calibration. The results from the calibration and validation of SWAT provided sufficient evidence that coupling SWAT and ANN improved prediction of the flow.

Table 1. Parameter sensitivity analysis.

\begin{tabular}{|c|c|c|c|c|c|c|}
\hline \multirow{2}{*}{ Parameter Name } & \multirow{2}{*}{ Description } & \multirow{2}{*}{ Range } & \multicolumn{2}{|c|}{ Degree of sensitivity } & \multirow{2}{*}{ Rank } & \multirow{2}{*}{$\begin{array}{l}\text { Fitted } \\
\text { Value }\end{array}$} \\
\hline & & & t-stat & p-value & & \\
\hline CN2.mgt & SCS runoff curve number for moisture condition II & $35-98$ & 15.829 & 0.0000 & 1 & 62 \\
\hline SHALLST.gw & Initial depth of water in the shallow aquifer [mm] & $0-5000$ & 4.001 & 0.0000 & 2 & 105 \\
\hline GW_SPYLD.gw & Specific yield of the shallow aquifer $\left[\mathrm{m}^{3} / \mathrm{m}^{3}\right]$ & $0-0.4$ & 3.485 & 0.0005 & 3 & 0.125 \\
\hline RCHRG_DP.gw & Deep aquifer percolation fraction [fraction] & $0-1$ & 3.255 & 0.0012 & 4 & 0.009 \\
\hline GWQMN.gw & $\begin{array}{l}\text { Threshold depth in the shallow aquifer required for return flow } \\
{[\mathrm{mm}]}\end{array}$ & $0-5000$ & 3.165 & 0.0016 & 5 & 48.47 \\
\hline CH_N2.rte & Manning's $n$ value for main channel & $-0.01-0.3$ & 3.120 & 0.0019 & 6 & 0.099 \\
\hline SOL_AWC.sol & Soil available water storage capacity $[\mathrm{mm} \mathrm{H} 2 \mathrm{O} / \mathrm{mm}$ soil] & $0-1$ & 2.95 & 0.0032 & 7 & 0.192 \\
\hline GW_DELAY.gw & Groundwater delay time [days] & $0-500$ & 2.847 & 0.0046 & 8 & 29 \\
\hline SURLAG.bsn & Surface runoff lag time [days] & $0-24$ & 2.504 & 0.0126 & 9 & 1.63 \\
\hline ESCO.bsn & Soil evaporation compensation factor & $0-1$ & 2.367 & 0.0183 & 10 & 0.32 \\
\hline CH_K2.rte & Effective hydraulic conductivity in the main channel $[\mathrm{mm} / \mathrm{h}]$ & $-0.01-500$ & 2.092 & 0.0369 & 11 & 0.082 \\
\hline EPCO.hru & Plant uptake compensation factor & $0-1$ & 2.067 & 0.0392 & 12 & 0.912 \\
\hline ALPHA_BF.gw & Base flow alpha factor [days] & $0-1$ & 1.941 & 0.0527 & 13 & 0.45 \\
\hline SOL_K.sol & Saturated hydraulic conductivity $[\mathrm{mm} / \mathrm{h}]$ & $0-2000$ & 1.909 & 0.0567 & 14 & 24.73 \\
\hline GW_REVAP.gw & Groundwater revap. coefficient & $0.02-0.2$ & -1.615 & 0.1068 & 15 & 0.07 \\
\hline DEEPST.gw & Initial depth of water in the deep aquifer [mm] & $0-10000$ & 1.515 & 0.1302 & 16 & 2172 \\
\hline REVAPMN.gw & $\begin{array}{l}\text { Threshold depth of water in the shallow aquifer for 'revap' to } \\
\text { occur [mm] }\end{array}$ & $0-1000$ & 1.308 & 0.1914 & 17 & 1.63 \\
\hline CANMX.hru & Maximum canopy storage $[\mathrm{mm}]$ & $0-100$ & 0.497 & 0.6189 & 18 & 28 \\
\hline
\end{tabular}

\subsection{SWAT_ANN Simulated Mean Annual Discharge for the Period (1978-2017)}

Figure 5 presents variations of mean annual discharge simulated under the LULC of 1978 with the climatic scenarios of the period (1978-2017) at Upper Njoro Catchment. The figure indicates a fair response of discharge peaks associated with extreme events of precipitation. This is consistent with the fact that out of all the climate variables, precipitation dominates as the major streamflow input in a catchment. The years with high amounts of precipitation also showed relatively higher events of streamflow peaks. The wetter climatic scenarios contribute to antecedent moisture conditions that have the potential for higher runoff and water yield generation. And this explains higher streamflow in 1978, 1979, 1981, 1982, 1985, 1997, 1998, 2003, 2004, 2010, and 2012. Unlike wetter climatic conditions, drier climatic scenarios are characterized by warmer periods. Warmer air can hold more moisture, more water is also sucked into the atmosphere from the ground and from plants through evaporation and transpiration. As the warmer atmosphere pulls more moisture from soils and plants, drought conditions are exacerbated during periods of low precipitation hence low flows.
This explains the extreme reduction of streamflow in 1980, 1984, 1987, 1992, 1999, 2000, and 2009. From the simulation, results of climate variability under the baseline climatic scenario (19781987) and LULC of 1978 on streamflow at Upper Njoro Catchment revealed that on average, streamflow reduced by $29.41 \%$ and $8.82 \%$ in the second and third decades. And, increased by $11.76 \%$ in the fourth decade. Streamflow reduction in the $2^{\text {nd }}$ and $3^{\text {rd }}$ decades was attributed to the decline of surface runoff and water yield. Surface runoff reduction in the $2^{\text {nd }}$ and $3^{\text {rd }}$ climatic scenarios implied a decreased number of wet years as a result of the progressive decline in precipitation. The decrease of average annual water yield in the second and third decades was attributed to a decline in surface runoff and recharge of groundwater due to the increase of actual evapotranspiration. Moreover, an increase in evapotranspiration was associated with positive trends in surface temperatures and solar radiation. Streamflow increase in the last decade was contributed by the relatively higher increase of water yield in the last decade as a result of an increased number of wet years, and more surface runoff, lateral flow, percolation, and groundwater flow. These results were consistent with the findings of the previous research [31, 32]. 


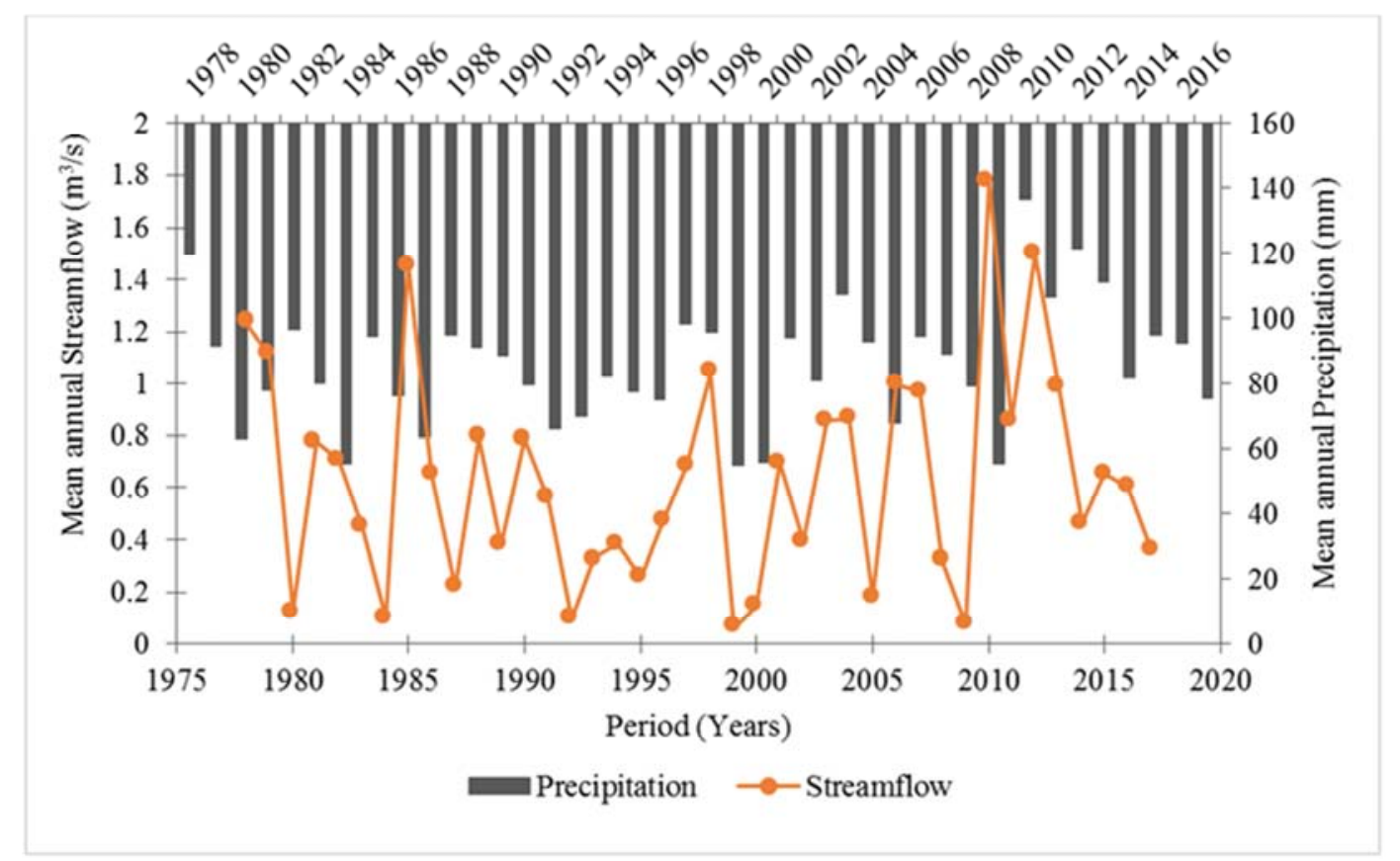

Figure 5. Mean annual simulated Discharge-Precipitation relationship at Upper Njoro Catchment for the period (1978-2017).

\subsection{Assessment of SWAT_ANN Potential in Modeling Influence of Climate Variability}

Results of mean monthly differences between the observed and simulated streamflow under the influence of climate variability with no changes in LULC of 1978 are shown in Figures 6 and 7. The figures indicate that the significant point of deviation of simulated from observed monthly streamflow occurred from 1985 onwards with the declining trend. The negative trend implied a decline in observed monthly discharges, which was attributed to the influence of changes in LULC since the effects of climate variability had been filtered out. While surface runoff decreased under the effect of climate variability (simulated discharge) in April (1990) and May (1998), the same months had the highest increase of surface runoff. This implies that the decrease of surface runoff caused by climate variability was offset by the increase of surface runoff due to the effect of LULC in the catchment, which would mean that the soil moisture storage capacity required to trigger runoff at the start of precipitation was inadequate. It portrays a characteristic of the waterstressed catchment [27].

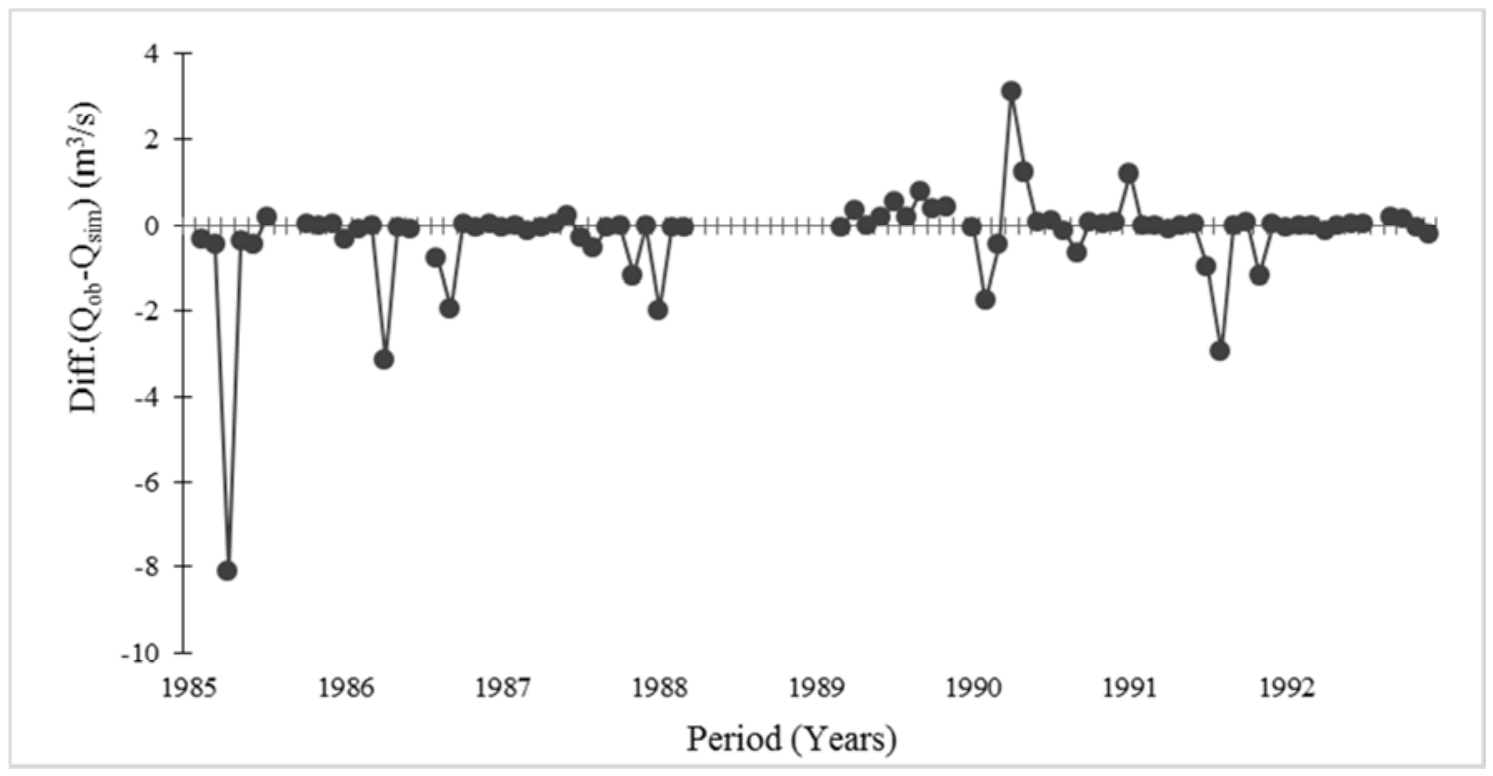

Figure 6. Mean monthly differences between observed and simulated streamflow (1985-1992). 


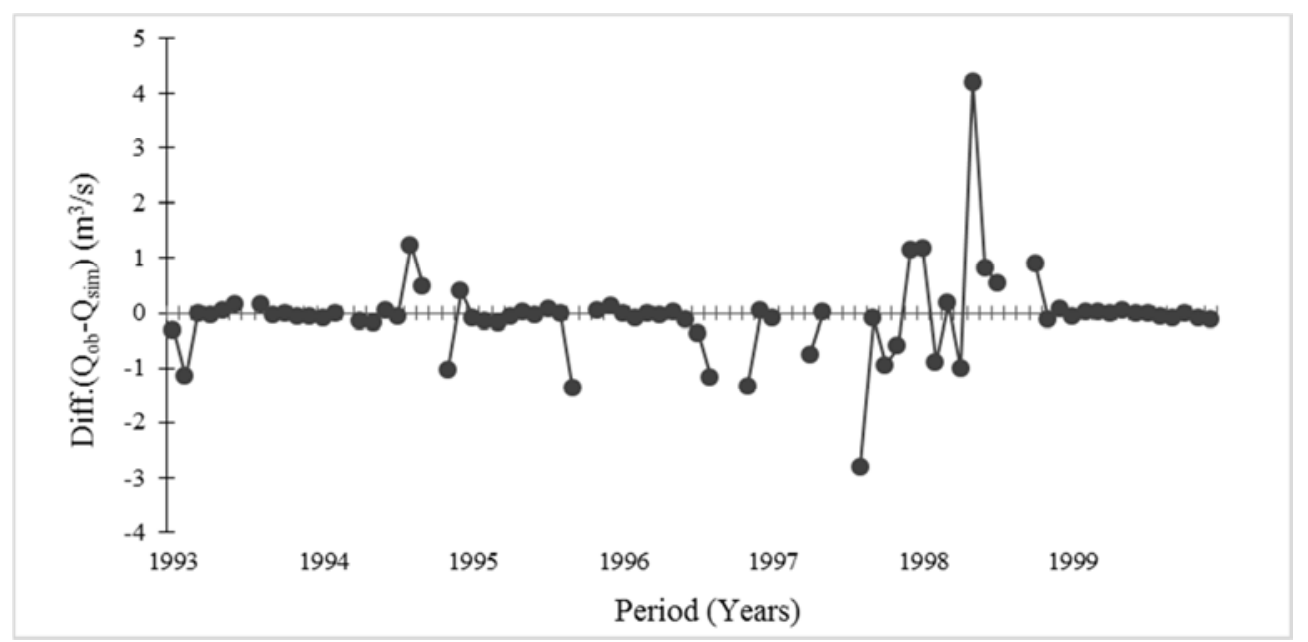

Figure 7. Mean monthly differences between observed and simulated streamflow (1993-1999).

Therefore, the modeling approach (SWAT_ANN) of separating the influence of climate variability on river regime from the effect of human activities could only be appropriate and satisfactory if by 1985 noticeable changes in LULC had already begun. The trends in the values of Figures 6 and 7 obtained were then compared with the trends in LULC changes. As shown in Figure 8, significant LULC changes began in 1986 to 2002 . The changes included deforestation and the conversion of forested areas into small-scale (mixed) agriculture. From 1986 to 2002, forest decreased by $24 \%$, Mixed Agricultural and pasture fields increased to cover about 27\%. Baldyga et al. [4] which analyzed spatial and temporal land cover changes reported significant changes in LULC from 1986 to 2003. Similarly, the changes they cited included deforestation and the expansion of agricultural lands. A study by Mwetu [31] on the analysis of LULC changes in 1973, 1986, and 2000 at the Upper Njoro Catchment also confirmed the rapid loss of forest. The study found that forest decreased by $22 \%$ from 1973 to 2000 and agricultural fields increased to cover about $10 \%, 16 \%$, and $25 \%$ of the total Upper Njoro Catchment in 1973, 1986, and 2000 respectively. Riparian Zone and bare land increased to cover about 3.2\% and 3.3\% of the total Upper Njoro Catchment. Mwetu [31] results were an improvement of an earlier record of $58 \%$ obtained by Baldyga et al. [4]. The findings were consistent with other previous research like Kundu [27] and Wambua [45] which reported excessive removal of forest in the Eastern Mau forest after 1986.

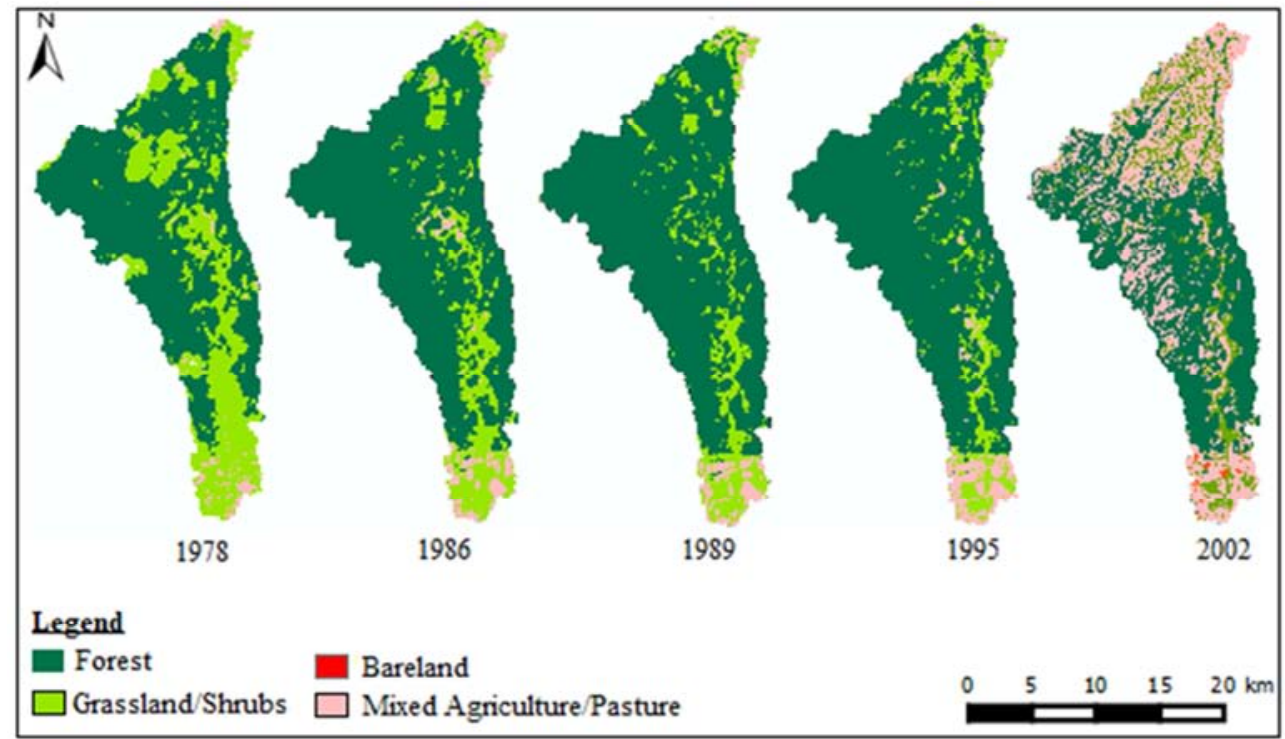

Figure 8. Upper Njoro Catchment supervised land cover classification.

Although there are several studies on land use and land cover influence on catchment hydrology, the evidence from the various studies is still contradictory. Some of the previous studies hold that an increase of the annual discharge is caused by deforestation and a decrease of the annual discharge is caused by afforestation $[8,10,14]$, which is not the case from studies such as $[15,27,29,39,46]$. For instance, a study by Kundu [27] on the application of remote sensing and GIS techniques to evaluate the impact of land use and land cover on streamflow in River Njoro Catchment found that as land- 
use changes from forest to rural built-up lands, urban lands and subsistence agriculture, surface runoff increases while surface and groundwater quantity and quality deteriorates. The effect is manifested in reduced natural recharge, reduced streamflow, and elimination of wetlands. Similarly, Mwetu [31] on the analysis of fluxes of annual water yield due to LULC change from 1973-2000 in River Njoro catchment found a negative trend as a response to deforestation.

Generally, changes in LULC influence soil physical properties. Furthermore, mean weight diameter, infiltration capacity, total porosity, available water content, and saturated hydraulic conductivity vary significantly for various land-use systems [11]. A study conducted by Amisi [1] on the analysis of event-based soil hydrological response for different landuse types in Upper Njoro Catchment found that deforested land had the lowest infiltration capacity and highest water repellency, forested land had the highest bulk density, mean saturated hydraulic conductivity, porosity, and organic matter content.

The higher infiltration rates in forested land because of the Duff and O horizon, would imply a delayed hydrological response leading to the realization of frequent recharge of streamflow thus higher annual discharge as compared to other land-use systems. The areas under bare land may experience excess surface runoff in the form of flash floods because of low infiltration rates due to the formation of soil sealing as a result of deforestation impacts (compaction, pore-clogging, and slaking) [3,35]. The inability of water to infiltrate the upper layers leads to reduced efficiency in storage and decrease in subsurface flows which in turn reduces recharge to streamflow hence a decline in annual discharge in the long run.

With regards to the findings of the aforementioned trends in LULC and documented studies on LULC and its influence on annual discharge at Upper Njoro Catchment, coupling SWAT, and ANN a hybrid approach was found to be a better option in modeling climate variability influence on annual river discharge variations or river regime. The obtained results in this work indicated that combining SWAT and ANN could enrich the hydrologic modeling environment by excluding the calibration, validation, and sensitivity analysis which can be, complicated, technical, hectic, and timeconsuming for the climate change impact studies. The information and knowledge obtained from this kind of modeling technique besides aiding the parameter transferability, detection of LULC point of change, can also be suitable in the attribution of changes in streamflow to climate variability and land-use alteration in a sub-catchment which is very crucial in water resources management.

\section{Conclusion}

The study aimed at modeling climate variability influence on the annual river discharge variations by coupling SWAT and ANN models. Statistical indicators showed that the modeling approach of combining SWAT with ANN had better prediction accuracy than when SWAT was used alone.
Monthly simulated streamflow from SWAT_ANN was further evaluated by comparing trends in the differences between observed and simulated against the quantified LULC changes and results in the documented land use and land cover changes. The results indicated that SWAT_ANN was capable of separating the effect of climate variability on the discharge from the overall influence which could be contributed by both changes in climate and land use. Therefore, the outcome of this study demonstrated that the modeling approach (SWAT_ANN) can be applied by the local water resources authorities to obtain the reasons for changes in monthly and annual river discharges.

\section{Acknowledgements}

I take this prerogative to express my humble gratitude to the Center of Excellence in Sustainable Agriculture and Agribusiness Management (CESAAM), the Faculty of Engineering and Technology, and Christ's Gift Academy (CGA), Mbita for the support.

\section{References}

[1] Amisi, L. (2018). Analysis of event-based soil hydrologic response for different land-use types in Upper Njoro river catchment (Masters Dissertation, Egerton University).

[2] Arnold, J. G., Moriasi, D. N., Gassman, P. W., Abbaspour, K. C., White, M. J., Srinivasan, R.,... \& Kannan, N. (2012). SWAT: Model use, calibration, and validation. Transactions of the ASABE, 55 (4), 1491-1508.

[3] Assouline, S., \& Mualem, Y. (2000). Modeling the dynamics of soil seal formation: Analysis of the effect of soil and rainfall properties. Water Resources Research, 36 (8), 23412349.

[4] Baldyga, T. J. (2005) Assessing Land Cover Change Impacts in Kenya's River Njoro Watershed Using Remote Sensing and Hydrologic Modelling. MSc Thesis, University of Wyoming, Laramie.

[5] Bao, Z., Zhang, J., Wang, G., Fu, G., He, R., Yan, X.,... \& Zhang, A. (2012). Attribution for decreasing streamflow of the Haihe River basin, northern China: climate variability or human activities? Journal of Hydrology, 460, 117-129.

[6] Benson, R. D., Tarlock, A. D., James, N., Getches, D. H., \& Bates, S. F. (2014). Water resource management. Foundation Press.

[7] Devia, G. K., Ganasri, B. P., \& Dwarakish, G. S. (2015). A review on hydrological models. Aquatic Procedia, 4, 10011007.

[8] Dias, L. C. P., Macedo, M. N., Costa, M. H., Coe, M. T., Neill, C., 2015. Effects of land cover change on evapotranspiration and strm, eamflow of small catchments in the Upper Xingu River Basin, Brazil. J. Hydrol.: Reg. Stud. 4B, 108-122.

[9] Fan, M., \& Shibata, H. (2015). Simulation of watershed hydrology and stream water quality under land use and climate change scenarios in Teshio River watershed, northern Japan. Ecological Indicators, 50, 79-89. 
[10] Farley, K. A., Jobbagy, E. G., Jackson, R. B., 2005. Effects of afforestation on water yield: a global synthesis with implications for policy. Glob. Change Biol. 11 (10), 15651576.

[11] Haghighi, F., Gorji, M., \& Shorafa, M. (2010). A study of the effects of land use changes on soil physical properties and organic matter. Land Degradation \& Development, 21 (5), 496-502.

[12] Hamidreza, J., Ahmadian, A., Golkar, M. A., Elkamel, A., \& Almansoori, A. (2018). Solar Irradiance Forecasting Based on the Combination of Radial Basis Function Artificial Neural Network and Genetic Algorithm.

[13] Hayati, M., \& Shirvany, Y. (2007). ANN approach for short term load forecasting for Illam region $\|$.

[14] Hayhoe, S., Neill, C., Porder, S., McHorney, R., Lefebvre, P., Coe, M., Elsenbeer, H., Krusche, A., 2011. Conversion to soy on the Amazonian agricultural frontier increases streamflow without affecting stormflow dynamics. Glob. Change Biol. 17 (5), 1821-1833. http://dx.doi.org/10.1111/j.13652486.2011.02392.x.

[15] Githui, F., Mutua, F., Bauwens, W., 2009. Estimating the impacts of land-cover change on runoff using the soil and water assessment tool (SWAT): case study of Nzoia catchment, Kenya. Hydrol. Sci. J 54, 899-990. http://dx.doi.org/10.1623/hysj.54.5.899.

[16] Goyal, M. K. \& Ojha, C. S. P. (2010). Analysis of mean monthly rainfall runoff data of Indian catchments using dimensionless variables by neural network. Journal of Environmental Protection, 1 (02), 155.

[17] Isik, S., Kalin, L., Schoonover, J. E., Srivastava, P., \& Lockaby, B. G. (2013). Modeling effects of changing land use/cover on daily streamflow: an artificial neural network and curve number based hybrid approach. Journal of Hydrology, 485, 103-112.

[18] Jacobs, J. H., Angerer, J., Vitale, J., Srinivasan, R., \& Kaitho, R. (2007). Mitigating economic damage in Kenya's upper Tana River basin: an application of Arc-View SWAT. Journal of Spatial Hydrology, 7 (1).

[19] Jajarmizadeh, M., Lafdani, E. K., Harun, S., \& Ahmadi, A. (2015). Application of SVM and SWAT models for monthly streamflow prediction, a case study in South of Iran. KSCE Journal of Civil Engineering, 19 (1), 345-357.

[20] Jayakrishnan, R. S. R. S., Srinivasan, R., Santhi, C., \& Arnold J. G. (2005). Advances in the application of the SWAT model for water resources management. Hydrological Processes: An International Journal, 19 (3), 749-762.

[21] Jimeno-Sáez, P., Senent-Aparicio, J., Pérez-Sánchez, J., \& Pulido-Velazquez, D. (2018). A Comparison of SWAT and ANN models for daily runoff simulation in different climatic zones of Peninsular Spain. Water, 10 (2), 192.

[22] Kalin, L., Isik, S., Schoonover, J. E., Lockaby, B. G., 2010. Predicting water quality in unmonitored watersheds using artificial neural networks. JEQ 39 (4), 1429-1440.

[23] Khalid, K. (2017). SWAT and ANN model hydrological assessment using Malaysia soil data (Doctoral dissertation, Universiti Teknologi MARA).

[24] Khashei, M., \&Bijari, M. (2010). An artificial neural network (p, d, q) model for timeseries forecasting. Expert Systems with applications, 37 (1), 479-489.

[25] Khoi, D. N., \& Thom, V. T. (2015). Parameter uncertainty analysis for simulating streamflow in a river catchment of Vietnam. Global ecology and conservation, 4, 538-548.

[26] Kişi, Ö. (2008). River flow forecasting and estimation using different artificial neural network techniques. Hydrology Research, 39 (1), 27-40.

[27] Kundu, P. M. (2007) Application of Remote Sensing and GIS Techniques to Evaluate the Impact of Land Use and Land Cover Change on Stream Flows: The Case for River Njoro Catchment in Eastern Mau-Kenya. PhD Thesis, Egerton University, Njoro.

[28] Mango, L. M., Melesse, A. M., McClain, M. E., Gann, D., \& Setegen, S. G. (2010). Land use and climate change impacts on the hydrology of the upper Mara River Basin, Kenya: results of a modeling study to support better resource management.

[29] Marhaento, H., Booij, M. J., \& Hoekstra, A. Y. (2016). Attribution of changes in stream flow to land use change and climate change in a mesoscale tropical catchment in Java, Indonesia. Hydrology Research, 48 (4), 1143-1155.

[30] Moriasi, D. N., Arnold, J. G., Van Liew, M. W., Bingner, R. L., Harmel, R. D., \& Veith, T. L. (2007). Model evaluation guidelines for systematic quantification of accuracy in watershed simulations. Transactions of the ASABE, 50 (3), 885-900.

[31] Mwetu, K. K. (2010). Modelling Responses of Hydrology to Land Use/ Land Cover Change and Climate Variability: A case of River Njoro Catchment of Kenya: Doctoral Thesis. University of Natural Resources and Applied Sciences, Vienna.

[32] Mwetu, K. K. (2019). Influence of Land Cover Changes and Climatic Variability on Discharge Regime of Njoro River Catchment in Kenya. Open Access Library Journal, 6 (7), 1-22.

[33] Noori, N. \& Kalin, L. (2016). Coupling SWAT and ANN models for enhanced daily streamflow prediction. Journal of Hydrology, 533, 141-151.

[34] Neitsch, S. L., Arnold, J. G., Kiniry, J. R., \& Williams, J. R. (2011). Soil and water assessment tool theoretical documentation version 2009. Texas Water Resources Institute.

[35] Okelo, M. O., Onyando, J. O., Shivoga, W. A., \& Miller, S. N. (2015). Assessment of infiltration using a mini rainfall simulator in the river njoro watershed. In Proceedings of Taal 2007: The 12th World Lake Conference. 777, 786-796.

[36] Liu, J. (2013). Radial Basis Function (RBF) neural network control for mechanical systems: design, analysis and Matlab simulation. Springer Science \& Business Media.

[37] Renner, M., Brust, K., Schwärzel, K., Volk, M., \& Bernhofer, C. (2014). Separating the effects of changes in land cover and climate: a hydro-meteorological analysis of the past $60 \mathrm{yr}$ in Saxony, Germany. Hydrology and Earth System Sciences, 18, $389-405$.

[38] Rezaeianzadeh, M., Tabari, H., Yazdi, A. A., Isik, S., \& Kalin, L. (2014). Flood flow forecasting using ANN, ANFIS and regression models. Neural Computing and Applications, 25 (1), 25-37. 
[39] Rodriguez, D. A., Tomasella, J., Linhares, C., 2010. Is the forest conversion to pasture affecting the hydrological response of Amazonian catchments? Signals in the Ji-Paraná Basin. Hydrol. Process. 24, 1254-1269. http://dx.doi.org/10.1002/hyp.7586.

[40] Rouholahnejad, E., Abbaspour, K. C., Vejdani, M., Srinivasan, R., Schulin, R., \& Lehmann, A. (2012). A parallelization framework for calibration of hydrological models. Environmental Modelling \& Software, 31, 28-36.

[41] Rwigi, S. K., 2014. Assessment of Potential Impacts of Climate Change and Deforestation on Surface Water Yields from the Mau Forest Complex Catchments in Kenya. University of Nairobi, Kenya PhD thesis, (July), 204p.

[42] Schipper, T. C. (2017). The attribution of changes in streamflow to climate and land use change for 472 catchments in the United States and Australia (Master's thesis, University of Twente).

[43] Senent-Aparicio, J., Jimeno-Sáez, P., Bueno-Crespo, A.,
Pérez-Sánchez, J., \& Pulido-Velázquez, D. (2019). Coupling machine-learning techniques with SWAT model for instantaneous peak flow prediction. Biosystems engineering, 177, 67-77.

[44] SP Ojha, C., Kumar Goyal, M., \& J Adeloye, A. (2010). Downscaling of precipitation for lake catchment in arid region in India using linear multiple regression and neural networks. The open hydrology Journal, 4 (1).

[45] Wambua, R. M. (2008). Determination of spatial distribution of runoff and sediment yield within Njoro catchment, Kenya. Masters degree Thesis, Faculty of Engineering and technology, Egerton University, Kenya.

[46] Webb, A., Jarrett, B., Turner, L., 2007. Effects of plantation forest harvesting on water quality and quantity: Canobolas State Forest, NSW. In: Wilson, A., Deehan, R., Watts, R., Page, K., Bownan, K., Curtis, A. (Eds.), Proceedings of the 5th Australian Stream Management Conference, Australian Rivers: Making a Difference. Charles Sturt University: Thurgoona, Australia. 